\title{
Genetic and clinical characterization of $B R C A$-associated hereditary breast and ovarian cancer in Navarra (Spain)
}

\author{
Ainara Ruiz de Sabando 1,2,3 므, Edurne Urrutia Lafuente ${ }^{1,2}$, Fermín García-Amigot ${ }^{1,3}$, Angel Alonso Sánchez ${ }^{1,2,3}$, \\ Lourdes Morales Garofalo', Sira Moreno ${ }^{1}$, Eva Ardanaz ${ }^{3,4,5}$ and Maria A. Ramos-Arroyo ${ }^{1,3^{*}}$
}

\begin{abstract}
Background: Genetic testing for BRCA1/2 genes is widely used as a strategy to reduce incidence and morbidity of hereditary breast and ovarian cancer ( $\mathrm{HBOC}$ ). The purpose of this study is to analyse the demographic and molecular characteristics of BRCA germline mutations in Navarra, Spain, and to investigate the clinical profile of hereditary and sporadic breast cancer (BC) and ovarian cancer (OC) in the Community.

Methods: The study includes 1246 individuals assessed for BRCA1/2 genetic testing in Navarra, during 2000-2016, and a cohort of BC $(n=4384)$ and OC $(n=561)$ from the population-based Navarra Cancer Registry. Distribution and molecular characteristics of BRCA1/2 mutations, as well as, comparative analysis of the clinical course, pathologic features and overall survival (OS) of patients in different risk groups were investigated.

Results: BRCA mutation detection rate was 16\%, with higher proportion (63\%) of BRCA2 families. Nineteen per cent of mutations were recurrent, one of which, BRCA2 c.6024dupG, showed high association to OC. BRCA carriers had double risk (95\% Cl $=1.04-4.33)$ of developing multiple malignancies than low risk families and were diagnosed at a much earlier age (16.6 and 11.7 years difference for $B C$ and $O C$, respectively) when compared to the general population. For $B C, B R C A$ carriers showed a more advanced histological stage, higher risk of bilateral neoplasms $(O R=4.3 ; 95 \%$ $\mathrm{Cl}=1.3-11.4$, for BRCA2 carriers) and worse OS rate at 5-, 10- and 15- years, than women with sporadic tumors. For OC, over $70 \%$ of patients of all risk groups showed advanced stages at diagnosis, with the highest among BRCA1 carriers (91\%). Furthermore, they also had higher probability of developing ovarian bilateral tumors (OR $=7.8$, $95 \% \mathrm{Cl}=1.7-55.7$, for $B R C A 1$ carriers) than the general population. Five-year OS rate was worse among women with sporadic OC than BRCA carriers, but it levelled out over the 15-year period.

Conclusions: In addition to national similarities in the HBOC-BRCA1/2 associated mutational spectrum, we identified a recurrent BRCA2 pathogenic variant (c.6024dupG), highly associated to OC in Navarra. Carriers of BRCA1/2 mutations showed a more severe $B C$ and $O C$ phenotype and had a worse overall prognosis when compared to a large cohort of women with sporadic counterpart tumors.
\end{abstract}

Keywords: Hereditary breast and ovarian cancer (HBOC), BRCA1/2, Recurrent mutations, Demographics, Sporadic breast and ovarian cancer, Laterality and stage of tumors, Overall survival, Navarra

\footnotetext{
* Correspondence: ma.ramos.arroyo@navarra.es

${ }^{1}$ Department of Medical Genetics, Complejo Hospitalario de Navarra (CHN),

Pamplona, Spain

${ }^{3}$ IdiSNA, Navarra Institute for Health Research, Pamplona, Spain

Full list of author information is available at the end of the article
}

(c) The Author(s). 2019 Open Access This article is distributed under the terms of the Creative Commons Attribution 4.0 International License (http://creativecommons.org/licenses/by/4.0/), which permits unrestricted use, distribution, and reproduction in any medium, provided you give appropriate credit to the original author(s) and the source, provide a link to the Creative Commons license, and indicate if changes were made. The Creative Commons Public Domain Dedication waiver (http://creativecommons.org/publicdomain/zero/1.0/) applies to the data made available in this article, unless otherwise stated. 


\section{Background}

About 32,800 breast (BC) and 3300 ovarian cancers (OC) are diagnosed every year in Spain, accounting for one third of the cancers among women [1-3]. Although survival has substantially improved over the past few years due to screening and the improvement of treatments, $\mathrm{BC}$ is the leading cause of cancer death among Spanish women, with about 6500 deaths in 2017, and OC is the fifth, with 2000 [4]. Between 5 and 10\% [5] of all BC and 13-15\% of OC $[6,7]$ are hereditary and approximately $25 \%$ are associated with the Hereditary breast/ovarian cancer (HBOC) syndrome, caused by abnormalities in the DNA repair genes $B R C A 1$ and $B R C A 2$ [8]. Inherited mutations in the BRCA1 and BRCA2 (BRCA1/2) cancer susceptibility genes convey high lifetime risks of $\mathrm{BC}$ and $\mathrm{OC}$, in the range of $40-66 \%$ and $13-46 \%$, respectively $[9,10]$, as well as, increased susceptibility for other malignancies, such as prostate and pancreatic cancers [11]. On the other hand, it has been hypothesized that $B R C A$-associated $\mathrm{BC}$ has a different prognosis as compared to the sporadic counterpart [12]. However, clinical findings regarding the prognostic role of $B R C A$ mutational status are still controversial.

Genetic testing for $B R C A 1 / 2$ mutations allows us to stratify families and individuals by their risk or predisposition to developing cancer, so that, preventive measurements can be offered to decrease cancer mortality and morbidity. Characterization of the most prevalent $B R C A 1$ and BRCA2 mutations and their geographical distribution can be useful in designing efficient mutational screening in a given population. Additionally, it is important to evaluate genetic testing and preventive programs for $\mathrm{HBOC}$, carrying out intermediate processes of data analysis and comparison of outcome indicators.

Previous studies have analysed the mutation spectrum of BRCA1/2 in different regions of Spain [13-19]. Navarra, with about 650,000 people in 2018 , has historically been in exchange with the neighbouring Basque territories in the north and Aragon and Castile in the southeast; additionally, in the last decades, it has experienced migration from other Spanish communities and countries. The aim of the present study is two-fold: a) to describe the molecular and demographic characteristics of families with HBOC syndrome in Navarra, Spain, b) to define the associated clinical phenotype and overall survival (OS) of individuals with $\mathrm{BC}$ and $\mathrm{OC}$ in different hereditary cancer risk families and the general population, in an attempt to provide indicators that may allow us to evaluate and improve the $\mathrm{HBOC}$ testing program in our community.

\section{Methods}

Hereditary breast/ovarian cancer study population

From 2000 to 2016, a total of 1246 individuals of Navarra, corresponding to 751 families with BC and/or
OC, were evaluated at the Hereditary Cancer Clinic of the Department of Medical Genetics of the Complejo Hospitalario de Navarra $(\mathrm{CHN})$, the reference public center for the HBOC program in the Autonomous Community. Since 2000, families with suspected familial/hereditary cancers are referred by medical specialists to the $\mathrm{CHN}$ for evaluation, counselling and genetic testing, if considered appropriate. Relevant information including personal and familial history, age of cancer diagnosis, tumor type and geographic family origin, is routinely obtained. Families are classified as high-risk families, if they meet the criteria established by the Breast Cancer Committee of the CHN (Additional file 1: Figure S1), or as low-risk families, if not. High-risk families are informed about their hereditary cancer risk, advised according to their personal and familial circumstances and offered genetic analysis of BRCA1 and BRCA2 genes. Additionally, members of $B R C A 1 / 2$ positive families that request genetic testing are studied and followed according to their individual risk status. All tested individuals provide a signed informed consent, following the appropriate genetic counselling. For this study, a disaggregated identification number was assigned to all participants to guarantee confidentiality and data protection. The study was approved by the Research Ethical Committee of Navarra.

\section{Origin of families}

Geographical origin of families was assessed by enquiring about the place of birth of parents and grandparents of index individuals. Positive $B R C A 1 / 2$ families were classified in one of the following geographic groups, based on the place of origin of their ancestors: a) Navarra, when the transmitting parent and/or grandparents were born in the Community of Navarra, b) neighbouring communities, when the transmitting parent and/or grandparents were from the surrounding communities of Navarra (Basque Country, Rioja, Soria, Zaragoza and Huesca), c) other Spanish communities, and d) other countries. The results were represented using the Geographic Information System QGIS version 3.0 Girona.

\section{Mutation analysis of $B R C A 1$ and $B R C A 2$}

Genomic DNA was extracted from peripheral blood of index cases of high-risk families. Sanger sequencing of BRCA1 and BRCA2 genes was performed using BigDye Terminator kits and read through 3500 Genetic Analyzer (Applied BioSystems). Mutational analysis was performed with SeqScape Software v3.0 (Thermo Fisher Scientific). All index patients were additionally tested for the presence of Large Genomic Rearrangements in BRCA1 and BRCA2 genes by Multiplex ligation-dependent probe amplification (MLPA). Specific probes for each exon of BRCA1 (SALSA MLPA P002 and P087 BRCA1 probemix, MRC-Holland) 
and BRCA2 genes (SALSA MLPA P045 BRCA2/CHEK2 probemix, MRC-Holland) were used. The fragments were measured by capillary electrophoresis using the 3500 Genetic Analyzer (Applied Biosystems) and analyzed with Coffalyzer (MRC-Holland).

\section{Variant nomenclature \& classification}

GenBank reference sequences of NM_007294.3 and NM_000059.3 were used for BRCA1 and BRCA2 analysis, respectively. Mutation nomenclature was described according to Human Genome Variation Society [20]. Pathogenicity of the mutations was assessed using the following databases: the Breast Cancer Information Core [21], the Universal Mutation Database [22] for BRCA1 and BRCA2, and ClinVar at NCBI [23]. For novel mutations the standards and guidelines of the American College of Medical Genetics and Genomics were followed to determine the possible disease-association [24]. In silico prediction was evaluated considering the impact of the amino acid changes as well as their conservation across species. These analyses were performed with the following bioinformatic tools: PROtein Variation Effect Analyzer (PROVEAN) [25], Polymorphism Phenotyping2 (PolyPhen-2) [26].

\section{Clinical and pathological features of $B R C A$ and non-BRCA related breast and ovarian cancer. Navarra Cancer Registry}

Individuals of Navarra are registered for health care and administrative purposes by a unique personal identification number in regional medical registries. This number was used to cross-link the information between the HBOC study and the Cancer Registry of Navarra, a regional registry that, since 1973, records all tumor malignancies of Navarra residents. We used this Registry as a reliable source of clinical information on a total of 596 participants of the HBOC study that had developed, at least, one infiltrating cancer, before January 2013. For comparison with tumors of sporadic origin, we also analysed a cohort sample of 4384 cases with BC and 561 with OC diagnosed in the general population from 2000 to 2012. The following variables were obtained: gender, number of infiltrating tumors per patient, age at diagnosis of each cancer, age at death, laterality, site, histology and stage of neoplasms. Site and histology were defined according to the International Classification of Diseases for Oncology (ICD-O) [27]. The extent of the disease was coded according to the Condensed TNM of the European Network of Cancer Registries [28].

\section{Statistics}

Statistical analysis was performed using IBM SPSS Statistics for Windows, Version 20.0 and OpenEpi [29]. Sociodemographic and clinical variables were summarized using descriptive statistics, such as mean and standard deviation $(\mathrm{SD})$ and frequencies and percentages. The associated risk of developing any tumor, of having bilateral tumor, and of having regional/advanced stage by HBOC group, compared with that of the general population (Cancer Registry), was estimated using odds ratios (OR), with 95\% confidence intervals. The association between selected clinical-pathological data and specific groups of HBOC, all categorical variables, was determined by using Chi-Square or Fisher's exact test, and Student's T test, as appropriate. Student's T test was used to compare independent continuous variables. Kaplan-Meier survival curves (proportion surviving) with 5-10- and 15-year survival were plotted, and log-rank test was used to compare different groups. Cox (hazard ratios, HR) regression was also performed, adjusting for age at diagnosis. All tests were two-sided and $p$-value less than 0.05 was considered to be statistically significant.

\section{Results \\ Hereditary breast/ovarian cancer study (2000-2016)}

Among the 751 evaluated families, residents of Navarra, with clinical and family history that suggested HBOC, 233 were classified as low-risk families, with no further analysis, and 518 others as high-risk families, for which mutational analysis was performed in the index affected member (Table 1). The number of cases included in the study is represented in Fig. 1, showing a remarkable increase of $B R C A 1 / 2$ testing and diagnosis over time.

From the high-risk group, 84 unrelated families (16.2\%), 228 individuals, were found carrying pathogenic mutations: 31 (37\%) in BRCA1 and 53 (63\%) in BRCA2. Of them, $39 \%$ of the transmitting parents or grandparents were originally from Navarra (33 families), 18\% came from the neighbouring communities (15 families) and the remaining families (42\%) had ancestors from other communities (34 families) or countries (2 families) (Fig. 2). Frequency of mutations in $B R C A 2$ gene was higher than in $B R C A 1$ in all geographic groups, and more so in families of local ancestors, in which two thirds $(67 \%)$ of them were $B R C A 2$ positive.

$B R C A 1$ families $(n=31)$ carried a total of 23 different mutations (Additional file 2: Table S1); two were recurrent mutations and 21 were unique mutations. The most frequent mutation was c.5123C $>$ A, present in eight apparently unrelated families, followed by c.211A $>$ G, identified in two families, representing a 26 , and $7 \%$, respectively, of the total families with $B R C A 1$ mutations.

Among BRCA2 positive families $(n=53), 29$ different mutations were observed (Additional file 3: Table S2). Eight were recurrent mutations and 21 unique mutations. Variant c.2806_2809delAAAC was highly represented (11 unrelated families). The five most frequent 
Table 1 Total number of subjects and families included in the hereditary breast/ovarian cancer (HBOC) study

\begin{tabular}{llllll}
\hline & Total & HBOC Study & & \\
\cline { 3 - 6 } & & $\begin{array}{l}\text { High risk BRCA1+ } \\
n(\%)\end{array}$ & $\begin{array}{l}\text { High risk BRCA2+ } \\
n(\%)\end{array}$ & $\begin{array}{l}\text { High risk BRCA- } \\
n(\%)\end{array}$ & $\begin{array}{l}\text { Low risk } \\
n(\%)\end{array}$ \\
\hline No. Families & 751 & $31(4.1 \%)$ & $53(7.1 \%)$ & $434(57.8 \%)$ & $233(31 \%)$ \\
No. Individuals & 1246 & $94(7.5 \%)$ & $135(10.8 \%)$ & $648(52 \%)$ & $369(29.6 \%)$ \\
\hline
\end{tabular}

pathogenic variants accounted for $50 \%$ of $B R C A 2$ mutations.

Four novel, unreported, pathogenic mutations, responsible for early-onset $\mathrm{BC}$ and $\mathrm{OC}$ were identified.

\section{BRCA1 c.4343delG (exon 13)}

This deletion, located in exon 13, results in a frame shift variant that originates a stop codon in position 1455 . The index patient in this family was a male, diagnosed of $\mathrm{PC}$ at age 67 with family history of $\mathrm{BC}$ and $\mathrm{OC}$ on the mother's side. BCs were diagnosed at ages 90 (mother) and 55 (maternal aunt) and OC at age 42 (maternal aunt).

\section{BRCA1 exon 5-7 duplication}

This variant was found in a 54 year old woman diagnosed with invasive ductal carcinoma. Her mother died of BC at 46. Two additional family members (a maternal cousin and her daughter), carriers of the same mutation, suffered from BC at ages 33 and 34, respectively.

\section{BRCA2 c.4132_4133delAC (exon 11)}

This alteration triggers a frame shift variant resulting in a stop codon in position 1380. The index patient, who inherited the mutation from her father, was diagnosed with invasive ductal carcinoma at 40 years old and a few

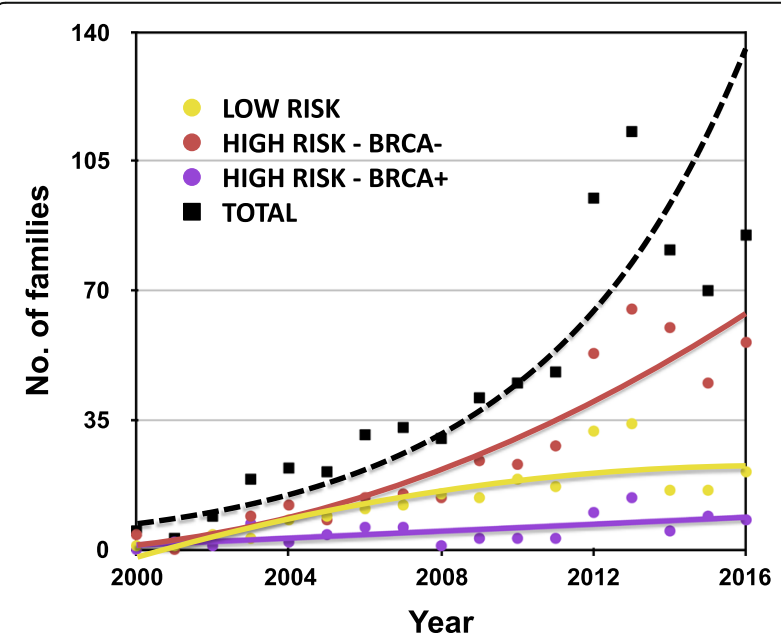

Fig. 1 Number of families included in the hereditary breast/ovarian cancer study (2000-2016) months after she also developed cervix cancer. Two of her paternal aunts died of BC.

\section{BRCA2 C.5216_5218insAAA (exon 11)}

This insertion originates a nonsense mutation with a stop codon in position 1739. The index patient was a woman that developed $\mathrm{BC}$ at 28 years old, whose mother, carrier of the mutation, had $\mathrm{OC}$ at the age of 60 .

\section{Clinical data from the Navarra Cancer Registry}

Of all the 1246 individuals in the HBOC study, 593 were included in the Navarra Cancer Registry with a total of 693 tumor entries. Twenty four (4\%) patients were males and $9(37.5 \%)$ of them carried a BRCA deleterious mutation.

The frequency of multiple tumors was significantly higher among BRCA1/2 carriers (21.6\%) than in individuals of the low-risk families (11.5\%), with an OR of 2.11 (95\% CI $=1.04$ to $4.33, p=0.038$ ) (Table 2). The difference did not reach statistical significance when compared with the high risk $B R C A$-negative group (HR-BRCA-negative). $B R C A 1$ and $B R C A 2$ mutations were associated with a different range of tumors. Cancer affecting breast, ovary, skin (SC), endometrium (EC), pancreas (PC) and prostate (PrC) accounted for $91.2 \%$ of all tumors registered in $B R C A 1 / 2$ patients and $93.7 \%$ among HR-BRCA-negative and low risk cases. $B R C A 1$ carriers had a higher frequency of OC (24.1\%), SC (11.1\%) and PC (3.7\%) than individuals in the other three groups (9.3, 5.3 and $0 \%$, respectively). $\mathrm{BC}(70.7 \%)$ and $\operatorname{PrC}(2.7 \%)$, however, were overrepresented in BRCA2 carriers compared to BRCA1-positives (55.6 and $0 \%$, respectively).

Among men, there were 3 BRCA1 mutation carriers who developed PC (1) and SC (2), and 6 BRCA2 positive cases, presenting with a wide variety of tumors: breast (4), prostate gland (2), lung (1), colon (1), fossa piriform (1) and thyroid gland (1). Three of the 9 BRCA1/2 male mutation carriers, developed multiple tumors, all associated with BRCA2.

To further study severity of the disease we analysed laterality, stage of the tumor, age at diagnosis and overall survival (OS) in patients of the HBOC study in comparison with a cohort sample of BC $(n=4384)$ and OC $(n=$ 561 ) in the general population. As shown in Table 3, all four risk groups of the $\mathrm{HBOC}$ study showed a higher 


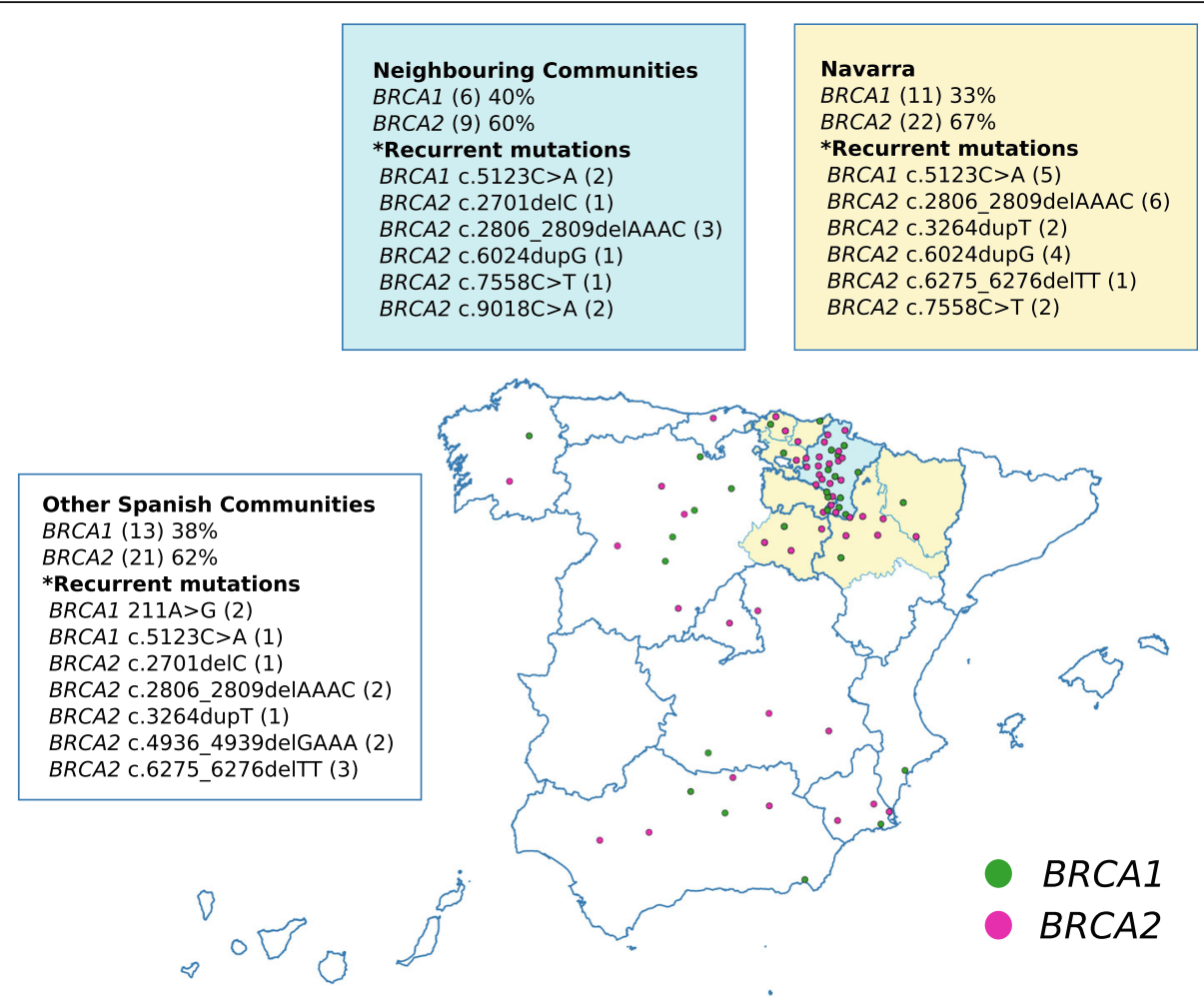

Fig. 2 Geographical origin of the hereditary breast/ovarian cancer families in Navarra. (Map created with QGIS 3.0)

Table 2 Number and type of malignancies among individuals of the hereditary breast/ovarian cancer (HBOC) study

\begin{tabular}{|c|c|c|c|c|c|c|}
\hline & & \multirow[t]{2}{*}{ Total } & \multicolumn{4}{|l|}{ HBOC study } \\
\hline & & & $\begin{array}{l}\text { High risk BRCA1+ } \\
n(\%)\end{array}$ & $\begin{array}{l}\text { High risk BRCA2+ } \\
n(\%)\end{array}$ & $\begin{array}{l}\text { High risk BRCA- } \\
n(\%)\end{array}$ & $\begin{array}{l}\text { Low risk } \\
n(\%)\end{array}$ \\
\hline \multirow[t]{15}{*}{ Navarra Cancer Registry } & \multicolumn{6}{|c|}{ Patients with one or more tumors } \\
\hline & Single tumor & $506(85.3 \%)$ & $33(78.6 \%)$ & $47(78.3 \%)$ & $303(86.1 \%)$ & $123(88.5 \%)$ \\
\hline & Multiple tumors (a) & $87(14.7 \%)$ & $9(21.4 \%)$ & $13(21.7 \%)$ & $49(13.9 \%)$ & $16(11.5 \%)$ \\
\hline & Total & 593 & 42 & 60 & 352 & 139 \\
\hline & \multicolumn{6}{|c|}{ (a) $B R C A 1 / 2$ vs Low Risk: $\mathrm{OR}=2.1195 \% \mathrm{Cl}=1.04$ to $4.33, p$-value $=0.038$} \\
\hline & \multicolumn{6}{|c|}{ Tumors by affected tissue } \\
\hline & BREAST & $531(76.6 \%)$ & $30(55.6 \%)$ & $53(70.7 \%)$ & $327(80.5 \%)$ & $120(76.4 \%)$ \\
\hline & OVARY & $55(7.9 \%)$ & $13(24.1 \%)$ & 7 (9.3\%) & 27 (6.6\%) & $8(5.1 \%)$ \\
\hline & SKIN & $46(6.6 \%)$ & $6(11.1 \%)$ & $4(5.3 \%)$ & $24(5.9 \%)$ & $12(7.6 \%)$ \\
\hline & ENDOMETRIUM & $13(1.9 \%)$ & $1(1.8 \%)$ & $2(2.7 \%)$ & $7(1.7 \%)$ & $3(1.9 \%)$ \\
\hline & PANCREAS & $5(0.7 \%)$ & $2(3.7 \%)$ & 0 & 0 & $3(1.9 \%)$ \\
\hline & COLON & $5(0.7 \%)$ & 0 & $1(1.3 \%)$ & $4(1 \%)$ & 0 \\
\hline & PROSTATE GLAND & $3(0.4 \%)$ & 0 & $2(2.7 \%)$ & 0 & $1(0.6 \%)$ \\
\hline & OTHERS & $35(5.1 \%)$ & $2(3.7 \%)$ & $6(8 \%)$ & $17(4.2 \%)$ & $10(6.4 \%)$ \\
\hline & TOTAL & 693 & 54 & 75 & 406 & 157 \\
\hline
\end{tabular}


Table 3 Clinical characteristics of breast and ovarian cancer cases included in the study

\begin{tabular}{|c|c|c|c|c|c|c|}
\hline & \multicolumn{4}{|c|}{ Hereditary breast/ovarian cancer study } & \multirow{2}{*}{$\begin{array}{l}\text { Cancer } \\
\text { Registry }\end{array}$} & \multirow[t]{2}{*}{$P$-value } \\
\hline & $\begin{array}{l}\text { High risk BRCA1+ } \\
n(\%)\end{array}$ & $\begin{array}{l}\text { High risk } B R C A 2+ \\
n(\%)\end{array}$ & $\begin{array}{l}\text { High risk BRCA- } \\
n(\%)\end{array}$ & $\begin{array}{l}\text { Low risk } \\
n(\%)\end{array}$ & & \\
\hline \multicolumn{7}{|l|}{ Breast cancer } \\
\hline \multicolumn{7}{|l|}{ Laterality } \\
\hline Right & $11(37.9 \%)$ & $22(41.5 \%)$ & $153(48.1 \%)$ & $51(44 \%)$ & $2003(47.4 \%)$ & \\
\hline Left & $17(58.6 \%)$ & $27(50.9 \%)$ & $155(48.7 \%)$ & $61(52.6 \%)$ & $2142(50.7 \%)$ & \\
\hline Bilateral & $1(3.5 \%)$ & $4(7.6 \%)$ & $10(3.2 \%)$ & $4(3.5 \%)$ & $78(1.8 \%)$ & $0.021(a)$ \\
\hline Total & 29 & 53 & 318 & 116 & 4223 & \\
\hline \multicolumn{7}{|c|}{ (a) $B R C A 2+$ vs Cancer Registry: $\mathrm{OR}=4.3 ; 95 \% \mathrm{Cl}=1.3$ to 11.4} \\
\hline \multicolumn{7}{|l|}{ Stage } \\
\hline Localized & $10(40 \%)$ & $24(47.1 \%)$ & $154(57.2 \%)$ & $56(59.6 \%)$ & $2396(57 \%)$ & \\
\hline Regional & $13(52 \%)$ & $24(47.1 \%)$ & 105 (39\%) & $36(38.3 \%)$ & $1618(38.5 \%)$ & \\
\hline Advanced & $2(8 \%)$ & $3(5.9 \%)$ & $10(3.7 \%)$ & $2(2.1 \%)$ & $189(4.5 \%)$ & $0.043(b)$ \\
\hline Total & 25 & 51 & 269 & 94 & 4203 & \\
\hline \multicolumn{7}{|l|}{ (b) $B R C A 1 / 2$ vs Cancer Registry } \\
\hline \multicolumn{7}{|l|}{ Age at diagnosis in years } \\
\hline Mean (standard deviation) & $44.3(8.98)$ & $44.12(10.17)$ & $45.72(10.34)$ & $50.14(11.44)$ & $60.79(15.47)$ & \\
\hline Number & 30 & 53 & 327 & 120 & 4384 & \\
\hline$p$-value & $<0.001$ & $<0.001$ & $<0.001$ & $<0.001$ & Reference & \\
\hline \multicolumn{7}{|l|}{ Ovarian cancer } \\
\hline \multicolumn{7}{|l|}{ Laterality } \\
\hline Right & $1(11.1 \%)$ & 0 & $6(46.2 \%)$ & $3(60 \%)$ & $100(37.2 \%)$ & \\
\hline Left & $1(11.1 \%)$ & $2(66.7 \%)$ & $3(23.1 \%)$ & $2(40 \%)$ & 86 (32\%) & \\
\hline Bilateral & $7(77.8 \%)$ & $1(33.3 \%)$ & $4(30.8 \%)$ & 0 & $83(30.9 \%)$ & 0.007 (c) \\
\hline Total & 9 & 3 & 13 & 5 & 269 & \\
\hline \multicolumn{7}{|c|}{ (c) BRCA1+ vs Cancer Registry: $\mathrm{OR}=7.8 ; 95 \% \mathrm{Cl}=1.7$ to 55.7} \\
\hline \multicolumn{7}{|l|}{ Stage } \\
\hline Localized & $1(9.1 \%)$ & $1(25 \%)$ & $6(25 \%)$ & $2(28.6 \%)$ & $28(23 \%)$ & \\
\hline Advanced & $10(90.9 \%)$ & $3(75 \%)$ & $18(75 \%)$ & $5(71.4 \%)$ & $94(77 \%)$ & $0.43(d)$ \\
\hline Total & 11 & 4 & 24 & 7 & 122 & \\
\hline \multicolumn{7}{|l|}{ (d) BRCA1/2 vs Cancer Registry } \\
\hline \multicolumn{7}{|l|}{ Age at diagnosis in years } \\
\hline Mean (standard deviation) & $54.12(12.03)$ & $53.33(14.68)$ & $53.29(10.86)$ & $54.55(13.08)$ & $65.63(15.43)$ & \\
\hline Number & 13 & 7 & 27 & 8 & 561 & \\
\hline$p$-value & 0.007 & 0.078 & $<0.001$ & 0.057 & Reference & \\
\hline
\end{tabular}

incidence of bilateral $\mathrm{BC}$ compared to the general population, although only in the group of BRCA2 positives the difference reached statistical significance $(7.6 \%$ vs $1.8 \% ; p=0.021, \mathrm{OR}=4.3 ; 95 \% \mathrm{CI}=1.3$ to 11.4$)$. For $\mathrm{OC}$, $B R C A 1$ carriers had a much higher frequency of bilateral tumors $(77.8 \%)$ than individuals in the $B R C A 2$ positive (33.3\%), HR-BRCA negative (30.8\%), low-risk HBOC $(0 \%)$ and the general population $(30.9 \% ; p=0.007, \mathrm{OR}=$ $7.8 ; 95 \% \mathrm{CI}=1.7$ to 55.7 ).
The stage at diagnose of $\mathrm{BC}$ tumors was significantly more advanced $(p=0.043)$ in $B R C A 1 / 2$ patients than in sporadic tumors. Over $55 \%$ of tumors were at regional/advanced stage among BRCA carriers compared to 40.4 and $43 \%$ in the low risk HBOC and the general population, respectively. The same trend was observed for OC among BRCA1 carriers, although numbers were too small to reach statistical significance. 
Mean age at diagnose of $\mathrm{BC}$ and $\mathrm{OC}$ was lower in all four groups of the $\mathrm{HBOC}$ study than in the general population (Table 3, Fig. 3). BRCA1/2 carriers were diagnosed of BC 16.6 years earlier ( 44.2 vs 60.8 years), while for $\mathrm{OC}$ the time difference was 11.7 years (53.9 vs 65.6).

Survival over the course of 15 years was also studied. For BC, 5-10- and 15-year OS did not show significant differences among risk groups (Table 4). More than 64\% of BRCA carriers lived 15 or more years after diagnosis, a percentage similar to that observed in sporadic $\mathrm{BC}$. However, mean age at death differed between groups. $B R C A 1 / 2$ mutation carriers died 20 years earlier than $\mathrm{BC}$ patients from the general population, indicating that age at diagnosis could be a co-variant of prognosis $(\mathrm{HR}=$ $1.08 ; 95 \% \mathrm{CI}=1.07$ to $1.08 ; p<0.0001)$. Further analysis, adjusting by age at diagnosis, showed that BRCA1 and $B R C A 2$ carriers had a significant worse prognosis than individuals of the other groups (Fig. 4a), with HR of 3.2 (95\% $\mathrm{CI}=1.5$ to $6.7 ; p=0.002)$ and $2.6(95 \% \mathrm{CI}=1.5$ to $4.7 ; p=0.001)$ respectively, when compared with $\mathrm{BC}$ of sporadic origin.

For $\mathrm{OC}$, the general population showed worst 5-year OS rate (41\%), becoming, however, similar in all risk groups at 15 years after diagnosis, with OS rates of $20 \%$ in BRCA1 mutation carriers and $28 \%$ in the general population (Table 4, Fig. 4b). Mean age at death differed notoriously, but sample size was not sufficient to use the modelling approach as for BC analysis. Nevertheless, when we analysed OS only in patients diagnosed before the age of 65 years, no significant differences were observed among risk groups (data not shown).

\section{Discussion}

We present a demographic, clinical and molecular study of families with HBOC in Navarra (Spain), through the analysis of retrospective data collected by the Department of Medical of the CHN, and the Cancer Registry for the Autonomous Community.

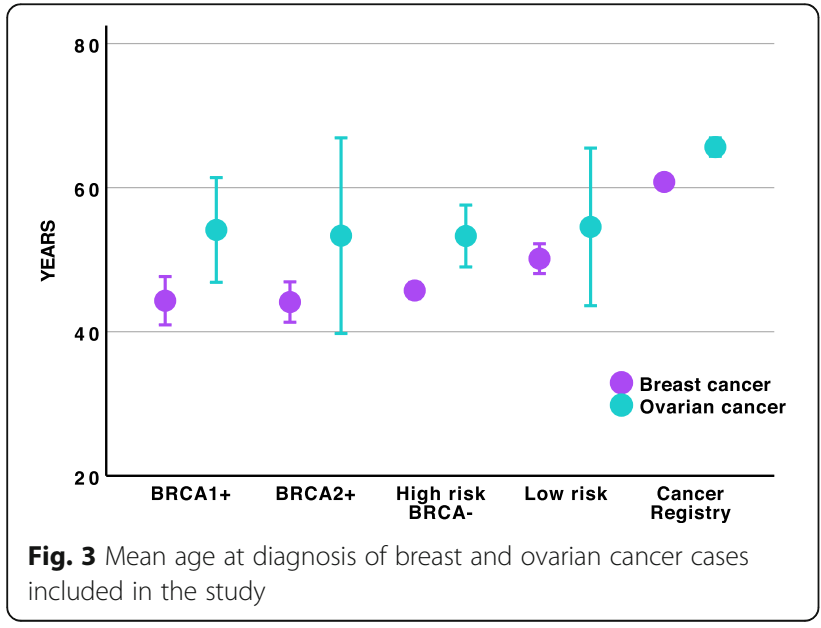

Mutations in BRCA1 and BRCA2 genes were identified in $16 \%$ of families (26\% of individuals) included in the high-risk HBOC sample. This rate is comparable with other studies $[14,18,19]$ and similarly shows a decreasing trend over time, moving from 30\% in 2000-2005, to 17\% during (2006-2010) and 14\% from 2011 to 2016. This is, most likely, due to the referral of the most severely affected families in the first years of cancer genetic services, and the use of less strict inclusion criteria in the later period, given the decrease in cost of the molecular analysis. It is noteworthy to highlight, however, the remarkable growth in the number of families and individuals assessed along the study period. Two thirds of the high-risk families were diagnosed in the last 6 years of the study, accounting for more than half of the families with pathogenic variants in BRCA1 and BRCA2.

Navarra is a small community in the North of Spain that has experienced important demographic changes since the 1950 decade, due to migration from other Spanish communities or countries. This mixed population could explain, at least in part, the similarities in $B R C A 1 / 2$ mutation distribution and spectrum with other areas of Spain $[17,19]$. As previously reported national wide, with the exception of Galicia and Asturias [13, 14], deleterious mutations in BRCA2 were more frequent than in $B R C A 1$, particularly among families of local ancestors in which $2 / 3$ of $B R C A$ associated families carried a $B R C A 2$ deleterious variant. Nineteen per cent (10/52) of pathogenic variants were recurrent and were responsible of $50 \%$ of HBOC families (Additional files 2 and 3: Tables S1 and S2). Many common mutations in Navarra are also frequent in other Spanish populations [14-18]. More so, many of the recurrent mutations in Navarra coincide with the most frequent $B R C A 1 / 2$ variants in Spain, as published in a recent international study [30].

In addition to these national similarities, $B R C A 1 / 2$ mutations in Navarra present some unique features. Recurrent deleterious variants show geographic clusters in more isolated regions. Our most frequent mutation, BRCA2 c.2806_2809delAAAC, is mainly distributed in the north-western mountainous lands, while the also frequent BRCA2 c.6024dupG is present in the southwestern riverbanks. Interestingly, $B R C A 2$ c.6024dupG and c.7558C $>\mathrm{T}$, are two recurrent mutations not reported previously in Spain. BRCA2 c.7558C $>\mathrm{T}$, also found (non-recurrently) in Sweden and Honduras [30], was detected in 8 carriers of three families and was associated to $6 \mathrm{BC}$ events. BRCA2 c.6024dupG was found in 16 carriers of 5 apparently unrelated families. This mutation, although never recurrently, has been reported mostly in Latin American countries [31], which may suggest a founder effect in the south-west of Navarra. This duplication has showed the highest correlation with OC in our study population: 4 out of the 7 BRCA2 
Table 4 Overall survival rates for breast and ovarian cancer

\begin{tabular}{|c|c|c|c|c|c|c|c|c|}
\hline & \multirow[t]{2}{*}{ Number } & \multirow{2}{*}{$\begin{array}{l}\text { Mean age } \\
\text { at death }\end{array}$} & \multicolumn{3}{|c|}{ Overall Survival } & \multirow{2}{*}{$\begin{array}{l}\text { Log Rank } \\
\text { test }\end{array}$} & \multicolumn{2}{|l|}{ Age adjusted } \\
\hline & & & 5-year & 10-year & 15-year & & Hazard Ratio (95\% Cl) & $P$-value \\
\hline \multicolumn{9}{|l|}{ Breast Cancer } \\
\hline BRCA1+ & 30 & $58.79 \pm 13.96$ & 0.863 & 0.823 & 0.640 & $p<0.001$ & $3.19(1.51,6.74)$ & 0.002 \\
\hline$B R C A 2+$ & 53 & $53.4 \pm 11.06$ & 0.882 & 0.786 & 0.703 & & $2.63(1.48,4.67)$ & 0.001 \\
\hline 2 High risk $B R C A-$ & 327 & $50.73 \pm 11.87$ & 0.948 & 0.899 & 0.840 & & $1.1(0.79,1.54)$ & 0.578 \\
\hline Low risk & 120 & $55.41 \pm 11.49$ & 0.967 & 0.936 & 0.874 & & $0.61(0.33,1.14)$ & 0.122 \\
\hline Cancer Registry & 4384 & $77.12 \pm 15.83$ & 0.818 & 0.724 & 0.651 & & Reference & \\
\hline \multicolumn{9}{|l|}{ Ovarian Cancer } \\
\hline$B R C A 1+$ & 13 & $62.68 \pm 13.43$ & 0.615 & 0.538 & 0.202 & $p<0.001$ & - & \\
\hline BRCA2+ & 7 & 53.93 & 0.857 & 0.857 & 0.857 & & & \\
\hline High risk $B R C A-$ & 27 & $64.1 \pm 10.05$ & 0.889 & 0.572 & 0.525 & & & \\
\hline Low risk & 8 & $64.46 \pm 12.27$ & 0.875 & 0.500 & 0.333 & & & \\
\hline Cancer Registry & 561 & $72.85 \pm 12.37$ & 0.408 & 0.321 & 0.276 & & & \\
\hline
\end{tabular}

positive $\mathrm{OC}$ identified in the $\mathrm{HBOC}$ study were associated to this mutation. In total, six mutation carriers developed ten different neoplasms, affecting ovary (4), breast (2), skin (1), endometrium (1), prostate (1) and lung (1). Three patients suffered multiple cancers. The information about the relationship between specific mutations in BRCA1/2 and the clinical expression is limited; however, there is evidence that mutations in the central part of BRCA2 (around exon 11), defined as the Ovarian Cancer Cluster Region, are associated with a higher OC risk and lower BC risk [32, 33]. Similarly, a Breast Cancer Cluster Region has been described at the end of BRCA2 (c.7394-c.8904) [33]. Our data from mutations BRCA2 c.6024dupG (exon 11) and c.7558C $>\mathrm{T}$, with high association to $\mathrm{OC}$ and $\mathrm{BC}$ respectively, support these evidences.

Many studies have investigated the prognosis role of $B R C A$ germ line mutations with inconsistent results. Some early studies suggested that $B R C A$ associated $B C$ and $\mathrm{OC}$ had a better prognosis than sporadic malignancies [34, 35], perhaps due to increased sensitivity to chemotherapy. BRCA1/2 function as tumor suppressor genes and their proteins play an important role in repairing damaged DNA [16]. Deficiency of BRCA1/2 proteins results in carcinomas with a diminished capacity to repair DNA and, presumably, decreased ability to repair DNA breaks caused by chemotherapy. BRCA1/ 2 mutation carriers seem to have an improved response to platinum-based chemotherapy [36]. However, whether the improved response translates into survival benefits still remains unclear.

More recent studies indicate that $B R C A$ mutations do not have a protective effect [37]. In our population, women with $\mathrm{BC}$ and $B R C A$ mutations had worse prognosis than those with sporadic cancer, diagnosed at the same age, with HR of 3.2 for BRCA1 and 2.6 for BRCA2. Goodwin et al [38] suggested that prognosis was best predicted by the characteristic of the cancer developed by each individual rather than by their carrier status. Evaluating the effects of tumor histology and treatmentrelated variables was not the purpose of this study. However, we found that age at diagnosis, laterality (in $B R C A 2$ carriers), tumor stage and presence of multiple neoplasms were significantly associated with $B R C A$ mutations. Interestingly, $\mathrm{BC}$ in HR-BRCA-negative and low-risk patients also presented at an earlier age than in the general population, but there were no significant differences with respect to the stage and laterality of the disease. On the other hand, their OS adjusted by age at diagnosis showed no differences with that of the general population, but it was significantly higher than in $B R C A 1 / 2$ carriers. These results may indicate that $B R C A$ carriers present with more aggressive or severe tumor characteristics, and, consequently, a worse prognosis than sporadic BC. We cannot rule out, however, that it might be the result of an increased disease burden in BRCA positive patients, as they are also prone to suffer from other malignancies, in addition to $\mathrm{BC}$.

In OC, diagnosis occurred 11-12 years earlier in all HBOC risk groups than in the general population, although only BRCA1-associated tumors were mostly bilateral and more advanced in tumor development. With respect to OS, sporadic OC seem to have a worse 5-year prognosis than BRCA associated carcinomas. Other studies also support the hypothesis of a protective OS effect of a BRCA1/2 mutation carrier versus a noncarrier [39]. However, we observed that over a 15 -year period, the apparent protective effect in $B R C A$ is no longer present. Similar results have been described by other authors [40] suggesting that for BRCA1/2 positive 


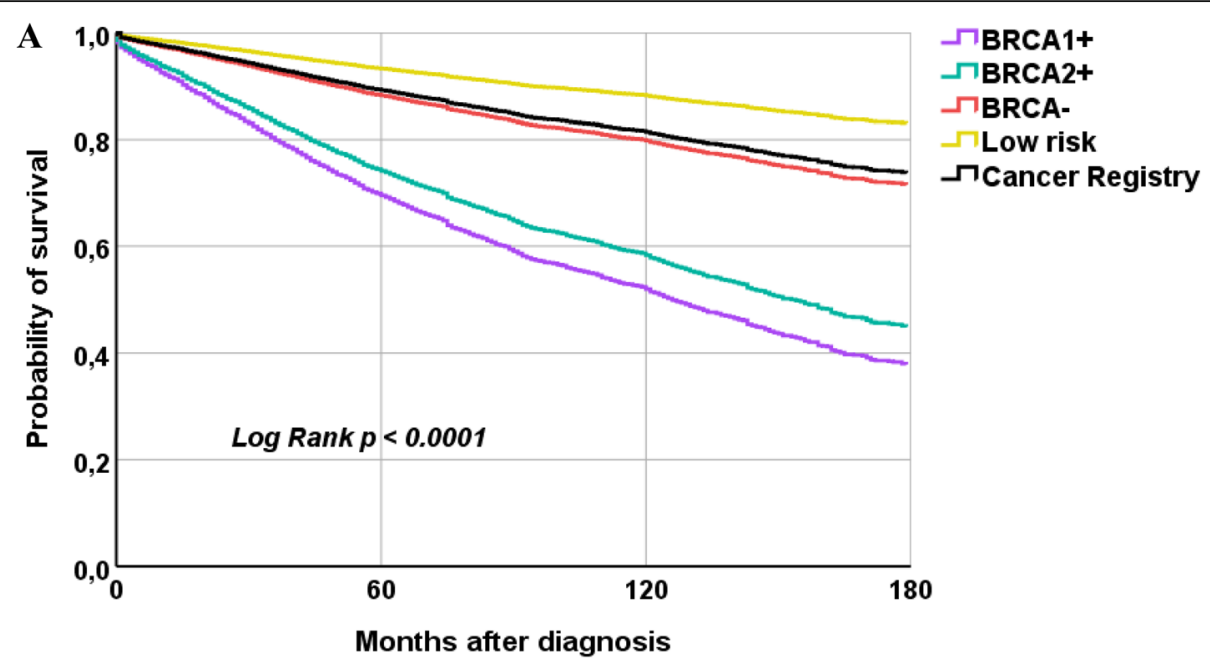

B

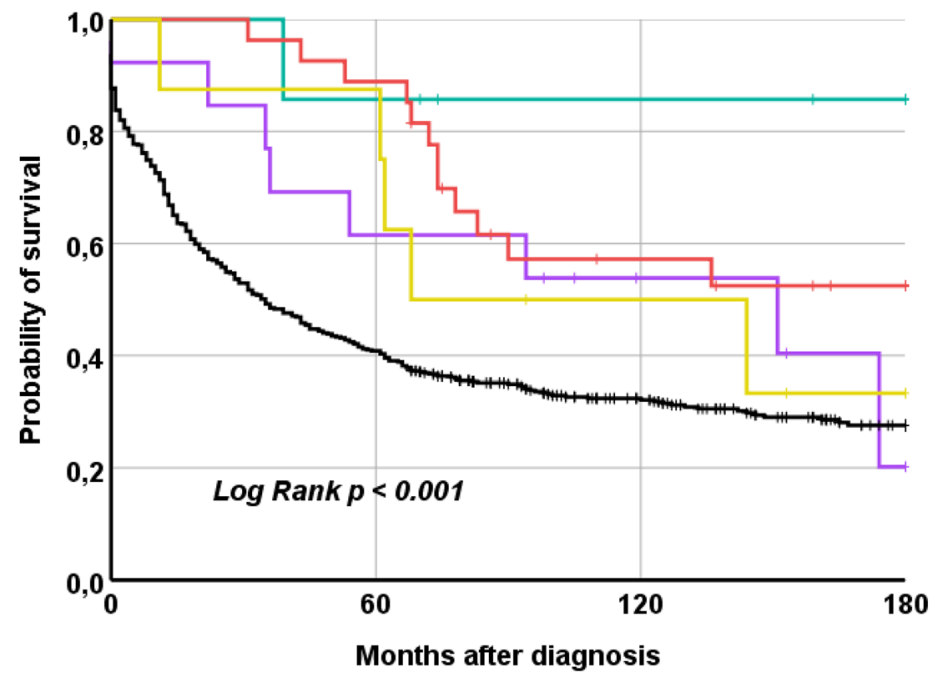

Fig. 4 Overall survival curves for breast and ovarian cancer. a Cox regression adjusted by age at diagnosis for breast cancer; b Kaplan-Meier curves for ovarian cancer

women with $\mathrm{OC}$, the short-term survival advantage does not lead to a long-term OS better prognosis.

Finally, it is interesting to mention that, as it is well known, most high-risk families for HBOC do not carry a $B R C A$ gene mutation [8]. However, they tend to share with them some of the phenotypic characteristics, such as, lower age at diagnosis and higher frequency of bilateral occurrence than cases in the low risk group and the general populations, which indicates that additional genetics and non-genetic factors remain to be identified.

This study has some strengths and limitations. It has an unbiased design with practically complete ascertainment of $B R C A$ carriers in the studied population, as the Department of Medical Genetics is the reference center for genetic testing in Navarra. Additionally, the study sample comprises a large population-based cohort of BC and $\mathrm{OC}$ with reliable clinical and outcomes data on
$B R C A$ and non-BRCA carriers. However, the small number of $B R C A$ families and cancer events in carriers may have limited the precision estimates of main effects and reduced statistical power of the study.

In summary, this retrospective study reviews $\mathrm{HBOC}$ due to mutations in $B R C A 1 / 2$ genes and describes the associated clinical and molecular features in Navarra. Additionally, it presents the state of the art of clinical practice for $\mathrm{HBOC}$ in our community, providing information on intermediate process and results indicators that will allow us to evaluate long-term efficiency of the cancer genetic testing program and its impact on public health.

\section{Conclusion}

The spectrum of $B R C A$ deleterious mutations in Navarra is similar to other Spanish regions, with some unique 
features. The possible founder effect of BRCA2 c.6024dupG and its high association with $\mathrm{OC}$ must be taking into account when performing genetic testing. Overall, severe phenotypic features such as early diagnosis, high tumor grading, occurrence of multiple malignancies and bilateral location, are more frequent among $B R C A$ carriers than in other cancer risk groups, conferring a poorer prognosis than those of sporadic origin. For $\mathrm{BC}, B R C A$ carriers have a worse OS rate at 5-, 10- and 15 years than cases from the general population. This study provides intermediate indicators that will help to further evaluate long-term prognosis of patients with HBOC and improve health care in our community.

\section{Supplementary information}

Supplementary information accompanies this paper at https://doi.org/10 1186/s12885-019-6277-x.

Additional file 1: Figure S1. Inclusion criteria of the hereditary breast/ ovarian cancer study.

Additional file 2: Table S1. BRCA1 mutations identified in this study. Germ line BRCA1 pathogenic mutations, molecular change, frequencies, geographical origin of the families ( $\mathrm{NC}=$ neighbouring communities; OSC = Other Spanish communities, OC = other communities) and associated tumors.

Additional file 3: Table S2. BRCA2 mutations identified in this study. Germ line BRCA2 pathogenic mutations, molecular change, frequencies, geographical origin of the families ( $\mathrm{NC}=$ neighbouring communities; OSC = Other Spanish communities, $\mathrm{OC}=$ other communities) and associated tumors

\section{Abbreviations}

BC: Breast Cancer; CDS: Coding DNA Sequence; CHN: Complejo Hospitalario de Navarra; Cl: Confidence Interval; EC: Endometrium Cancer; HBOC: Hereditary Breast and Ovarian Cancer; HR: Hazard Ratio; KM: KaplanMeier; LC: Lung Cancer; OC: Ovarian Cancer; OR: Odds Ratio; OS: Overall Survival; PC: Pancreatic Cancer; PrC: Prostate Cancer; SC: Skin Cancer; SD: Standard Deviation; TNM: Tumor, Node and Metastases

\section{Acknowledgements}

We would like to thank Asociación SARAY, as well as patients, families and referring physicians for their support and valuable contribution to the study. We would also like to acknowledge Berta Ibañez, from the Methodology Unit of Navarrabiomed and Sandra Eraso, from the Navarra Statistics Institute, for their assistance in the biostatistical analysis of the clinical and anatomopathological parameters and the use of QGIS Geographic Information System, respectively.

\section{Authors' contributions}

ARdS organized the databases, performed the data analysis and wrote the manuscript. FG-A and SM performed the mutational analysis and MLPA studies. EUL and EA managed the databases and extracted the information. AAS, LMG and MAR-A revised clinical data. MAR-A supervised the study and was a major contributor in writing the manuscript. All authors read and approved the final manuscript.

\section{Funding}

Asociación Navarra de Cáncer de Mama (SARAY). The grant supported a full time researcher for the completion of the study.

\section{Availability of data and materials}

The datasets used and/or analysed during the current study are available from the corresponding author upon reasonable request.

\section{Ethics approval and consent to participate}

The study was approved by the "Comité de Ética de la Investigación con medicamentos (CEIm)" of "Gobierno de Navarra". The project number is "Ptyo2019/42". All tested individuals provided a signed informed consent, following the appropriate genetic counselling.

\section{Consent for publication}

Not Applicable.

\section{Competing interests}

The authors declare that they have no competing interests.

\section{Author details}

${ }^{1}$ Department of Medical Genetics, Complejo Hospitalario de Navarra (CHN), Pamplona, Spain. ${ }^{2}$ Navarrabiomed, Pamplona, Spain. ${ }^{3}$ IdiSNA, Navarra Institute for Health Research, Pamplona, Spain. ${ }^{4}$ Navarra Public Health Institute, Pamplona, Spain. ${ }^{5}$ CIBER Epidemiology and Public Health CIBERESP, Madrid, Spain.

Received: 26 July 2019 Accepted: 20 October 2019

Published online: 27 November 2019

\section{References}

1. Asociación Española Contra el Cáncer [https://www.aecc.es/es]. Accessed 30 Sept 2019.

2. Sociedad Española de Oncología Médica [https://seom.org/]. Accessed 30 Sept 2019.

3. Red Española de Registros de Cáncer [http://redecan.org/es/index.cfm]. Accessed 30 Sept 2019.

4. Las cifras del cáncer en España 2019 [https://seom.org/dmcancer/wpcontent/uploads/2019/Informe-SEOM-cifras-cancer-2019.pdf]. Accessed 30 Sept 2019.

5. Campeau PM. Hereditary breast cancer: new genetic developments, new therapeutic avenues. Hum Genet. 2008;124:31-42.

6. Zhang S. Frequencies of BRCA1 and BRCA2 mutations among 1,342 unselected patients with invasive ovarian cancer. Gynecol Oncol. 2011;121:353-7.

7. Pal T. BRCA1 and BRCA2 mutations account for a large proportion of ovarian carcinoma cases. Cancer. 2005;104(2):2807-16.

8. Nielsen FC. Hereditary breast and ovarian cancer: new genes in confined pathways. Nat Rev Cancer. 2016;16(9):599-612.

9. Antoniou A. Average risks of breast and ovarian cancer associated with BRCA1 or BRCA2 mutations detected in case series unselected for family history: a combined analysis of 22 studies. Am J Hum Genet. 2003;75(5): 1117-30.

10. Chen S. Meta-analysis of BRCA1 and BRCA2 penetrance. J Clin Oncol. 2007;25(11):1329-33.

11. Cavanagh $\mathrm{H}$. The role of BRCA1 and BRCA2 mutations in prostate, pancreatic and stomach cancers. Hered Cancer Clin Pract. 2015;13(1):16.

12. Bordeleau L. Prognosis of BRCA-associated breast cancer: a summary of evidence. Breast Cancer Res Treat. 2010;119(1):13-24.

13. Vega A. Analysis of BRCA1 and BRCA2 in breast and breast/ovarian cancer families shows population substructure in the Iberian peninsula. Ann Hum Genet. 2002;66(Pt 1):29-36.

14. Blay P. Mutational analysis of BRCA1 and BRCA2 in hereditary breast and ovarian cancer families from Asturias (northern Spain). BMC Cancer. 2013;13:243.

15. Beristain E. Differences in the frequency and distribution of BRCA1 and BRCA2 mutations in breast/ovarian cancer cases from the Basque country with respect to the Spanish population: implications for genetic counselling. Breast Cancer Res Treat. 2007;106(2):255-6.

16. Duran M. Mutational analysis of BRCA2 in Spanish breast Cancer patients from Castilla-Leon: identification of four novel truncating mutations. Hum Mutat. 2003;21(4):448.

17. Diez O. Heterogeneous prevalence of recurrent BRCA1 and BRCA2 mutations in Spain according to the geographical area: implications for genetic testing. Familial Cancer. 2010;9:187-91.

18. Barrios XG. Molecular characterization and clinical interpretation of BRCA1/ BRCA2 variants in families from Murcia (South-Eastern Spain) with hereditary breast and ovarian cancer: clinical-pathological features in BRCA carriers and non-carriers. Familial Cancer. 2017;16:477-89. 
19. Pajares B. Hereditary breast and ovarian cancer in Andalusian families: a genetic population study. BMC Cancer. 2018;18(1):647.

20. Human Genome Variation Society [https://wnw.hgvs.org/]. Accessed 30 Sept 2019.

21. Breast Cancer Information Core [https://research.nhgri.nih.gov/bic/]. Accessed 30 Sept 2019.

22. Universal Mutation Database [http://www.umd.be/]. Accessed 30 Sept 2019.

23. ClinVar [https://www.ncbi.nlm.nih.gov/clinvar/]. Accessed 30 Sept 2019.

24. Richards S. Standards and guidelines for the interpretation of sequence variants: a joint consensus recommendation of the American College of Medical Genetics and Genomics and the Association for Molecular Pathology. Genet med. 2015;17(5):405-24.

25. PROtein Variation Effect ANalyzer (PROVEAN) [http://provean.jcvi.org/index. php]. Accessed 30 Sept 2019

26. Polymorphism Phenotyping-2 (PolyPhen-2) [http://genetics.bwh.harvard. edu/pph2/. Accessed 30 Sept 2019

27. World Health Organization, ICD-O - 3rd edition, 1st revision, 3rd ed. [https://www.who.int/iris/handle/10665/96612]. Accessed 30 Sept 2019.

28. Condensed TNM of the European Network of Cancer Registries [https://www.encr.eu/sites/default/files/pdf/extentofdisease.pdf]. Accessed 30 Sept 2019.

29. OpenEpi [https://www.openepi.com/]. Accessed 30 Sept 2019.

30. Rebbeck TR. Mutational Spectrum in a worldwide study of 29,700 families with BRCA1 or BRCA2 mutations. Hum Mutat. 2018;39(5):593-620.

31. Jara L. Mutations in BRCA1, BRCA2 and other breast and ovarian cancer susceptibility genes in central and south American populations. Biol Res. 2017;50(1):35.

32. Levy-Lahad E. Cancer risks among BRCA1 and BRCA2 mutation carriers. Br J Cancer. 2007:96(1):11-5.

33. Rebbeck TR. Association of Type and Location of BRCA1 and BRCA2 mutations with risk of breast and ovarian Cancer. JAMA. 2015;313(13):1347-61.

34. Verhoog LC. Survival and tumour characteristics of breast-cancer patients with germline mutations of BRCA1. Lancet. 1998;351(9099):316-21.

35. Cortesi L. Favourable ten-year overall survival in a Caucasian population with high probability of hereditary breast cancer. BMC Cancer. 2010;10:90.

36. Kriege M. Sensitivity to first-line chemotherapy for metastatic breast cance in BRCA1 and BRCA2 mutation carriers. J Clin Oncol. 2009;27(23):3764-71.

37. Schmidt MK. Breast Cancer Survival of BRCA1/BRCA2 Mutation Carriers in a Hospital-Based Cohort of Young Women. J Natl Cancer Inst. 2017;109(9): djw329.

38. Goodwin PJ. Breast Cancer Prognosis in BRCA1 and BRCA2 Mutation Carriers: An International Prospective Breast Cancer Family Registry Population-Based Cohort Study. J Clin Oncol. 2012;30(1):19-26.

39. Huang Y-W. Association of BRCA1/2 mutations with ovarian cancer prognosis. Syst Rev Metaanal. 2018;97(2):e9380.

40. McLaughlin JR. Long-term ovarian Cancer survival associated with mutation in BRCA1 or BRCA2. J Natl Cancer Inst. 2013;105(2):141-8.

\section{Publisher's Note}

Springer Nature remains neutral with regard to jurisdictional claims in published maps and institutional affiliations.

Ready to submit your research? Choose BMC and benefit from:

- fast, convenient online submission

- thorough peer review by experienced researchers in your field

- rapid publication on acceptance

- support for research data, including large and complex data types

- gold Open Access which fosters wider collaboration and increased citations

- maximum visibility for your research: over $100 \mathrm{M}$ website views per year

At BMC, research is always in progress.

Learn more biomedcentral.com/submissions 